\title{
A prospective study on gestational diabetes mellitus in a tertiary care center
}

\author{
Poovathi M., S. Gayathri Devi*
}

\begin{abstract}
Department of Obstetrics and Gynecology, Mahathma Gandhi Memorial Government Hospital attached to K.A.P.V Government Medical College, Trichy, Tamil Nadu, India
\end{abstract}

Received: 20 September 2018

Accepted: 01 November 2018

\author{
*Correspondence: \\ Dr. S. Gayathri Devi, \\ E-mail: gynaecgayathri@gmail.com
}

Copyright: (c) the author(s), publisher and licensee Medip Academy. This is an open-access article distributed under the terms of the Creative Commons Attribution Non-Commercial License, which permits unrestricted non-commercial use, distribution, and reproduction in any medium, provided the original work is properly cited.

\begin{abstract}
Background: Gestational Diabetes Mellitus is defined as any degree of glucose intolerance identified for the firsttime during pregnancy. Gestational Diabetes Mellitus is a highly prevalent metabolic disorder among pregnant woman with rising incidence in recent years. Various risk factors are associated with this disorder leading to maternal and neonatal mortality. About 5\% of the pregnancies are complicated by Gestational Diabetes Mellitus. The International Diabetes Federation estimates that one in six live birth $(16.8 \%)$ are to women with some form of hyperglycemia in pregnancy. The prevalence of GDM in present study is $4.326 \%$. Not only obesity but also overweight women have greatly increased risk of developing gestational diabetes.

Methods: This includes study all cases of gestational diabetes mellitus admitted in the Department of Obstetrics, Government Mahatma Gandhi Memorial Hospital attached to K.A.P.V medical college, Trichy. This study has been conducted from January 2018 to June 2018.Fetal complications in infants born to diabetic mothers were studied. Maternal complications related to Gestational diabetes were also studied.

Results: The total deliveries during this period were found to be 4085 of which 175 patients where diagnosed to have Gestational Diabetes Mellitus, thus the incidence accounts for $4.326 \%$.

The incidence in 20 to 25 years age group was around 67 which accounted for $37.3 \%$. Most cases less than 20 years were found to be pregestational diabetes mellitus. The prevalence of GDM in present study is $4.326 \%$. The maternal complications like vaginal infections accounted to $11.4 \%$, gestational hypertension accounts to $14.3 \%$, polyhydramnios to $17.1 \%$. Regarding the fetal complications incidence of intrauterine death at term was around $8 \%$ and neonatal complications included hyperbiliribinemia $11.4 \%$, hypoglycaemia, $6.7 \%$, respiratory distress syndrome $5.75 \%$.
\end{abstract}

Conclusions: Gestational diabetes was associated with increased adverse maternal and perinatal outcomes.

Keywords: Diabetes mellitus, Glucose intolerance, Maternal and fetal complications

\section{INTRODUCTION}

Gestational Diabetes Mellitus is defined as any degree of glucose intolerance identified for the first-time during pregnancy. ${ }^{1}$ Any form of glucose intolerance identified before pregnancy is termed as Pregestational Diabetes Mellitus. The prevelance of Gestational diabetes mellitus worldwide is debatable varying between population, race and the diagnostic criteria defined by each country.
International diabetes federation estimates that $16 \%$ of all live children born worldwide were exposed to hyperglycemia during pregnancy. ${ }^{2}$ During pregnancy maternal insulin sensitivity and glucose metabolism itself changes. Reduced insulin sensitivity occurs due to human, placental lactogenprogestrone, growth hormone. Risk factors include family history of diabetes in first degree relative, obesity, age more than 25 years. Neonatal complications include hypoglycemia, hypocalcemia, 
hyperbilirubinemia, cardiopulmonary and central nervous system.

According to the National Centre for Health statistics, the number of adults diagnosed with diabetes has tripled from 6.9 million in 1991 to 20.9 million in 2011. There is a keen interest in events that precede diabetes, and this includes the uterine environment, where early imprinting is believed to have effects in later life. For example, in utero exposure to maternal hyperglycemia leads to fetal hyperinsulinemia, causing an increase in fetal fat cells. This leads to obesity and insulin resistance in childhood which in turn leads to impaired glucose tolerance and diabetes in adulthood. The cycle of fetal exposure to diabetes leading to obesity and glucose intolerance has been reported in Pima Indians and Chicago population (Silverman 1995). A growing body of epidemiological evidence suggests a possible association between vitamin D deficiency/insufficiency and GDM, maternal obesity and adverse maternal, neonatal and infant outcome. The molecular and cellular mechanisms with respect to the interaction between vitamin D and GDM are only partly understood. However, it appears that vitamin D acts directly on pancreatic beta cells through expression of the vitamin $\mathrm{D}$ receptors as well as through the enzyme $25(\mathrm{OH}) \mathrm{D}-1$-alfa-hydroxylase by regulating intracellular calcium to increase insulin secretion and by attenuating systemic inflammation associated with insulin resistance.

The association between vitamin $\mathrm{D}$ and glucose metabolism in GDM has been investigated in several observational studies but large randomized controlled trials are lacking, and it remains to be determined whether vitamin D supplementation can reduce the risk of developing GDM and/or improve glycaemic control in diabetic pregnant women with vitamin D deficiency/insufficiency. $3,4,5$

The objectives of the present study were to observe the incidence of gestational diabetes mellitus during the study period, to evaluate the incidence of neonatal complications to neonates born to woman with gestational diabetes mellitus, to study the correlation between body mass index and incidence of gestational diabetes mellitus.

\section{METHODS}

This is a prospective study conducted in, Mahathma Gandhi Memorial Government Hospital attached to K.A.P.V Government Medical college Trichy, Tamilnadu, South India.

This is a tertiary health centre where we receive complicated obstetric cases, sometimes in early or sometimes in late stages. This study has been conducted from January 2018 to June 2018.

Total deliveries during this period was found to be 4085 of which 175 patients where diagnosed to have
Gestational Diabetes Mellitus, thus the incidence accounts for $4.326 \%$ of which patients on insulin accounted to $21 \%$, patients on Oral hypoglycemic agents like metformin accounted to $26 \%$ and patients on meal plan accounted to $52.3 \%$.

Maternal and fetal complications were more associated with patients with uncontrolled Gestational Diabetes Mellitus on insulin.

We in present study have analyzed the data of the antenatal woman which included age, parity, socioeconomic class, any risk factors associated, mode of termination of pregnancy, maternal morbidity in the form of intensive care admissions and number of days stayed there, post-partum complications like hypoglycemia, delayed wound healing, sepsis, post-operative paralytic ileus. The fetal outcome included incidence of hypoglycemia, hypocalcemia, hyperbilirubinemia, cardiopulmonary and central nervous system which required admission in neonatal intensive care units.

\section{Inclusion criteria}

- Women with glucose intolerance diagnosed for the first-time during pregnancy.

\section{Exclusion criteria}

- Women with overt diabetes mellitus.

\section{RESULTS}

The total deliveries during this period were found to be 4085 of which 175 patients where diagnosed to have Gestational Diabetes Mellitus, thus the incidence accounts for $4.326 \%$ of which patients on insulin accounted to $21 \%$, patients on Oral hypoglycemic agents like metformin accounted to $26 \%$ and patients on meal plan accounted to $52.3 \%$ (Table 1 ).

Table 1: Distribution based on glycaemic control.

\begin{tabular}{|lll|}
\hline Total GDM & Number & Percentage \\
\hline & 175 & 100 \\
\hline Insulin & 38 & 21.4 \\
\hline Meal plan & 91 & 52.2 \\
\hline Metformin & 46 & 26 \\
\hline
\end{tabular}

The Mode of termination by LSCS was $80 \%$ and by labour natural was $20 \%$ (Table 2).

Table 2: Distribution based on mode of termination.

\begin{tabular}{|lll|}
\hline Mode of termination & Number & Percentage \\
\hline LSCS & 140 & 80 \\
\hline Labour natural & 35 & 20 \\
\hline
\end{tabular}

Analysing neonatal complications, Respiratory distress syndrome is $5.75 \%$, Hypoglycaemia $6.8 \%$, 
hyperbilirubinemia is $11.4 \%$, macrosomia was $18 \%$ and intrauterine fetal death was $8 \%$. IUGR in present study was only $1.7 \%$ (Table 3 ).

Table 3: Distribution based on baby outcome and neonatal complications $(n=175)$.

\begin{tabular}{|lll|}
\hline Baby outcome & Number & $\%$ \\
\hline Anomalous baby & 7 & 4 \\
\hline Macrosomia & 32 & 18 \\
\hline Intrauterine growth retardation & 3 & 1.7 \\
\hline Intrauterine death & 15 & 8 \\
\hline Respiratory distress syndrome & 10 & 5.75 \\
\hline Hypoglycaemia & 12 & 6.89 \\
\hline Hyperbilirubinemia & 20 & 11.4 \\
\hline
\end{tabular}

Babies with birth weight $>4.00 \mathrm{~kg}$ were $11.4 \%$ (Table 4 ).

Table 4: Distribution based on weight of the baby $(n=175)$.

\begin{tabular}{|lll|}
\hline Birth weight & Number & Percentage \\
\hline$<2 \mathrm{~kg}$ & 9 & 4.29 \\
\hline $2-4 \mathrm{~kg}$ & 147 & 84.31 \\
\hline$>4 \mathrm{~kg}$ & 19 & 11.4 \\
\hline
\end{tabular}

The incidence of IUD was higher when the mean fasting blood glucose was >120 mg (Table 5).

Table 5: Intra uterine death based on glycaemic control $(n=15)$.

\begin{tabular}{lll} 
Blood glucose & Number & Percentage \\
$\begin{array}{l}\text { Fasting blood glucose }<120 \\
\text { mg/dl }\end{array}$ & 13 & 95 \\
\hline $\begin{array}{l}\text { Fasting blood glucose }>120 \\
\text { mg/dl }\end{array}$ & 2 & 5 \\
\hline
\end{tabular}

The incidence in 20 to 25 years age group was around 67 which accounted for $37.3 \%$. Most cases less than 20 years were found to be pregestational diabetes mellitus. (Table 6).

Table 6: Age wise distribution $(n=175)$.

\begin{tabular}{|lll|}
\hline Age group & Number & Percentage \\
\hline$<25$ years & 67 & 37.3 \\
\hline$>25$ years & 108 & 62.7 \\
\hline
\end{tabular}

Age was measured as a continuous variable and were categorised as 20 to 25 years, 25 to 30 years and more than 30 years.

More than half the women with Gestational Diabetes Mellitus were above 25 years (108) which accounts to about $62 \%$ of all cases. In present study only $9 \%$ were diagnosed during first trimester, $36 \%$ were diagnosed during second trimester $55 \%$ were diagnosed only during third trimester (Table 7).
Table 7: Distribution based on time of diagnosis $(n=175)$.

\begin{tabular}{|lll|} 
Trimester & Number & Percentage \\
\hline First & 15 & 9 \\
\hline Second & 64 & 36 \\
\hline Third & 96 & 55 \\
\hline
\end{tabular}

The incidence of Gestational Diabetes Mellitus is increased in women with body mass index $>30$ which is about $75 \%$ (Table 8 ).

Table 8: Distribution based on body mass index $(n=175)$.

\begin{tabular}{|lll|} 
Body mass index & Number & Percentage \\
\hline$<25$ & 13 & 7 \\
\hline $25-30$ & 31 & 18 \\
\hline$>30$ & 131 & 75 \\
\hline
\end{tabular}

The prevalence of GDM in present study is $4.326 \%$. The maternal complications like vaginal infections accounted to $11.4 \%$, gestational hypertension accountes to $14.3 \%$, polyhydramnios to $17.1 \%$. Women with GDM are at higher risk of hypertensive disorders including gestational hypertension, preeclampsia, and eclampsia (Table 9).

Table 9: Distribution based on maternal complications.

\begin{tabular}{|lll|}
\hline Complication & Number & Percentage \\
\hline Vaginal infections & 20 & 11.4 \\
\hline Gestational hypertension & 25 & 14.3 \\
\hline Polyhydramnios & 31 & 17.1 \\
\hline Post-operative wound infection & 40 & 22.8 \\
\hline Post-operative paralytic ileus & 5 & 2.8 \\
\hline
\end{tabular}

\section{DISCUSSION}

The incidence of gestational diabetes mellitus is increased in women with body mass index $>30$ which is about $75 \%$. Various authors have confirmed that not only obesity, but also overweight women have greatly increased risk of developing gestational diabetes. ${ }^{1,2}$ In a study by Zargar et al. determined the prevalence of GDM in Kashmiri women was $3.8 \%{ }^{1}$

The incidence of macrosomia in present study is $18 \%$, intrauterine growth retardation is $1.7 \%$, Respiratory distress syndrome is $5.75 \%$, Hypoglycaemia $6.8 \%$, hyperbilirubinemia is $11.4 \%$. similar findings were seen in various studies including Ganguly et al., Turki G. and Odar et al. in their respective studies. ${ }^{6-7}$

The prevelance of GDM in present study is $4.326 \%$, the maternal complications like vaginal infections accounted to $11.4 \%$, gestational hypertension accountes to $14.3 \%$, polyhydramnios to $17.1 \%$ which is similar to the study 
conducted by Ganguly et al., Turki G. and Odar et al. in their respective studies. ${ }^{6-8}$

Women with GDM are at higher risk of hypertensive disorders including gestational hypertension, preeclampsia, and eclampsia. In the HAPO study, 5.9\% had gestational hypertension and $4.8 \%$ had preeclampsia. The study showed that the glucose level at the first glucose tolerance test was positively correlated with the risk of preeclampsia. ${ }^{9}$

Recently two large randomized controlled trials have been carried out to prove that identification and treatment of GDM and even mild carbohydrate intolerance during pregnancy confer a benefit. Thus the Australian Carbohydrate Intolerance Study in Pregnant Women, a large, randomized trial of treatment for gestational diabetes mellitus, concluded that treatment reduces serious perinatal complications and may also improve health-related quality of life using treatment of gestational diabetes in the form of dietary advice, blood glucose monitoring, and insulin therapy as required for glycemiccontrol. $^{8}$ The American Maternal-Fetal Medicine Units Network study provided further compelling evidence that among women who have GDM and normal fasting glucose levels, treatment that includes dietary intervention and insulin therapy, as necessary, reduces rates of foetal overgrowth, caesarean delivery, and preeclampsia. ${ }^{9}$

Accordingly, the primary intervention recommended to women diagnosed with GDM is dietary counseling in combination with physical activity and self-monitoring of blood glucose. ${ }^{10,11}$ If these measures are insufficient in terms of achieving optimal glycemic control subcutaneous insulin therapy is the therapy of choice as insulin does not cross the placenta and is therefore considered harmless to the foetus. However, insulin is relatively expensive and difficult to administer. It requires education to ensure a safe administration and it is associated with an increased risk of hypoglycemia and weight gain. The use of safe and effective oral agents may therefore offer advantages over insulin but has not yet been formally approved for GDM therapy in all countries. $^{12}$ A large randomized controlled trial was performed by Rowan et al in which 751 women with GDM at 20 to 33 weeks of gestation were assigned to open treatment with metformin or insulin if lifestyle intervention had failed to achieve glycemic control. ${ }^{13}$ Three hundred and sixty-three women were assigned to metformin. $92.6 \%$ continued to receive Metformin until delivery and $46.3 \%$ in the Metformin group received supplemental insulin. The authors concluded that metformin, alone or with supplemental insulin, was not associated with increased perinatal complications as compared with insulin. Thus, the treatment with Metformin was considered safe and effective and moreover, the women preferred metformin to insulin treatment. Further follow-up data are however necessary to establish long-term safety. Another randomized controlled trial included 404 women between 11 and 33 weeks of gestation with singleton pregnancies and GDM that required treatment and assigned them to either glyburide or insulin. All the women received dietary advice and eight women in the glyburide group required additional insulin therapy. There were no significant differences between the glyburide and insulin groups regarding macrosomia, neonatal hypoglycemia, lung complications or foetal abnormalities and it was concluded that glyburide is a clinically effective alternative to insulin therapy. ${ }^{14}$

Other studies show that both metformin and sulfonylurea have been increasingly and safely used in the treatment of GDM. ${ }^{15}$ However, both glyburide and metformin cross the placenta and given the growing evidence of epigenetic foetal programming in utero, administration of drugs potentially affecting foetal metabolism is of major concern and as long term follow-up data on both mother and offspring are lacking oral anti hyperglycemic agents should be used with caution. ${ }^{16}$

\section{CONCLUSION}

The strategy recommended by the IADPSG for detection and diagnosis of hyperglycemic disorders in pregnancy is followed in our institute. Two discrete phases are included. The first is detection of women with overt diabetes not previously diagnosed or treated outside of pregnancy. Universal early testing is recommended in India. The second phase is a 75-g OGTT at 24-28 weeks' gestation in all women not previously found to have overt diabetes or GDM. Multidisciplinary team approach essential for better outcome of mother and fetus. In present study there is no maternal mortality during the study period

First prenatal visit: Measure FPG, A1C, or random plasma glucose on all or only high-risk women ${ }^{\dagger}$ If results indicate overt diabetes as per Treatment and follow-up as for preexisting diabetes. If results not diagnostic of overt diabetesand fasting plasma glucose $\geq 5.1 \mathrm{mmol} / \mathrm{l}$ (92 $\mathrm{mg} / \mathrm{dl})$ but $<7.0 \mathrm{mmol} / \mathrm{l}(126 \mathrm{mg} / \mathrm{dl})$, diagnose as GDM and fasting plasma glucose $<5.1 \mathrm{mmol} / \mathrm{l}(92 \mathrm{mg} / \mathrm{dl})$, test for GDM from 24 to 28 weeks' gestation with a $75-\mathrm{g}$ OGTT*

24-28 weeks' gestation: diagnosis of GDM: 2-h 75-g OGTT: perform after overnight fast on all women not previously found to have overt diabetes or GDM during testing earlier in this pregnancy, Overt diabetes if fasting plasma glucose $\geq 7.0 \mathrm{mmol} / \mathrm{l}(126 \mathrm{mg} / \mathrm{dl})$, GDM if one or more values equals or exceeds thresholds indicated in Normal if all values on OGTT less than thresholds indicated in

Funding: No funding sources Conflict of interest: None declared

Ethical approval: The study was approved by the Institutional Ethics Committee 


\section{REFERENCES}

1. Seshiah V1, Balaji V, Balaji MS, Sanjeevi CB, Green A. Gestational Diabetes Mellitus in India. J Assoc Physicians India.2004;52:707-11.

2. Zargar AH, Sheikh MI, Bashir MI, Masoodi SR, Laway BA, Wani AI, et al. Prevalence of gestational diabetes mellitus in Kashmiri women from the Indian subcontinent. Diab Res Clinic Prac. 2004;66(2):13945.

3. Poel YH, Hummel P, Lips PT, Stam F, Van Der Ploeg T, Simsek S. Vitamin D and gestational diabetes: a systematic review and meta-analysis. Europe J Int Med. 2012;23(5):465-9.

4. Alvarez JA, Ashraf A. Role of vitamin d in insulin secretion and insulin sensitivity for glucose homeostasis. Int J Endocrinol. 2010;2010:351385.

5. Kampmann U, Mosekilde L, Juhl C, Moller N, Christensen B, Rejnmark L et al. Effects of 12 weeks high dose vitamin D3 treatment on insulin sensitivity, beta cell function, and metabolic markers in patients with type 2 diabetes and vitamin D insufficiency - a double-blind, randomized, placebocontrolled trial. Metabolism. 2014;63(9):1115-24.

6. Ganguly, A. A Study of Diabetes Mellitus over 8 years. J Obstet Gynecol India.1995;45:27-31.

7. Gasim, T. (2012) Gestational Diabetes Mellitus: Maternal and Perinatal Outcomes in 220 Saudi Women. Oman Med J.2012;27(2):140-4

8. Crowther CA, Hiller JE, Moss JR, McPhee AJ, Jeffries WS, Robinson JS. Effect of treatment of gestational diabetes mellitus on pregnancy outcomes. N Engl J Med. 2005;352(24):2477-86.

9. Landon MB, Spong CY, Thom E, Carpenter MW, Ramin SM, Casey B, et al. A multicenter, randomized trial of treatment for mild gestational diabetes. N Engl J Med. 2009;361(24):1339-48.
10. Lapolla A, Dalfrà MG, Fedele D. Management of gestational diabetes mellitus. Diab metabol syndrome Obes: Targets Therapy. 2009;2:73.

11. Reader D, Splett P, Gunderson EP. Impact of gestational diabetes mellitus nutrition practice guidelines implemented by registered dietitians on pregnancy outcomes. J Am Diet Assoc. 2006;106(9):1426-43

12. Homko CJ, Reece EA. Insulins and oral hypoglycemic agents in pregnancy. J Mat Fet Neonat Med. 2006;19(11):679-86.

13. Rowan JA, Hague WM, Gao W, Battin MR, Moore MP. Metformin versus insulin for the treatment of gestational diabetes. N Engl J Med. 2008;358(19):2003-15.

14. Langer O, Conway DL, Berkus MD, Xenakis EM, Gonzales O. A comparison of glyburide and insulin in women with gestational diabetes mellitus. $\mathrm{N}$ Engl J Med. 2000;343(16):1134-8.

15. Dhulkotia JS, Ola B, Fraser R, Farrell T. Oral hypoglycemicagents vs insulin in management of gestational diabetes: a systematic review and metaanalysis. Am J Obstet Gynecol. 2010;203(5):457.e1-e9.

16. Hyperglycemia and Adverse Pregnancy Outcome (HAPO) Study Cooperative Research Group. Hyperglycemia and Adverse Pregnancy Outcome (HAPO) study: preeclampsia. Am J Obstet Gynecol. 2010;202(3):255.e1-.e7.

Cite this article as: Poovathi M, Devi SG. A prospective study on gestational diabetes mellitus in a tertiary care center. Int J Reprod Contracept Obstet Gynecol 2018;7:4972-6. 